\title{
From the Editor
}

I thoroughly enjoy children's books. Having four grandchildren has allowed me to keep up with the current books and to share some of the beloved books from my three children's and my childhood. Some of my all-time favorite books are: What Do You Do With an Idea?, If You Give a Mouse a Cookie, Where the Wild Things Are, I'll Love You Forever, The Rainbow Fish, and The Boxcar Children. Children's literature can be a powerful educational tool because these books can use images and words through engaging stories to convey messages. I am especially inspired by the book, What Do You Do With an Idea? which starts with, "One day, I had an idea. 'Where did it come from? Why is it here?' I wondered, 'What do you do with an idea?'. The book concludes with, "And then, I realized what you do with an idea ... You change the world" (Yamada, K. 2013).

The ideas in this issue of WORK, like all the other issues that proceed it, have the potential to "change the world" through the advancement of knowledge in the broad occupation of work.

This issue of WORK has three sections. The issue begins with a special section on Complementary and Integrative Medicine in Healthcare which was expertly guest edited by Dr. Valerie Rice. The section contains six articles with an introduction by Valerie, a dear friend and colleague.

The next section contains our monthly article on Ergonomics in a Global World titled: Range of Rest Posture of human lower limbs. This was a paper presented at the 2018 International Ergonomics Association (IEA) Congress in Florence, Italy.

Finally, the issue concludes with nine regular articles that take us around the globe on a variety of topics such as the effect of yoga on vigilance; selfrated sleep and state anxiety in border security force personnel in India; measuring perceived efficacy for coping with PTSD in the workplace; the bibliometric analysis of the body posture in relation to visual display terminals; and physical therapists with work-related musculoskeletal disorders in the state of Kuwait with a comparison across countries and health care professions.
We hope that you have been enjoying our webinar series, Learn at WORK. If you missed any of the webinars, you can find the recordings at the Learn at WORK YouTube channel: https://www.youtube. com/channel/UCOJalCXvSg9fPHaFFs48PuQ Here is the schedule for the upcoming 2019 Learn at WORK webinars:

\section{Wednesday, May 22, 2019, from 1pm-2pm Eastern Standard Time (EST):}

More than a job: Career development of individuals with cystic fibrosis presented by Pablo S. Saldana.

Registration link: https://attendee.gotowebinar.com/ register/6460900040982414594

Wednesday, June 12, 2019, from 1pm-2pm Eastern Standard Time (EST):

The efficacy and efficiency of disability management in job retention and job reintegration: A Systematic Review presented by Dominique Van de Velde.

Registration link: https://attendee.gotowebinar.com/ register/8674132286757505795

\section{Wednesday, August 21, 2019, from 1pm-2pm East- ern Standard Time (EST): \\ Perspectives on the use of a telehealth service- delivery model as a component of school-based occupational therapy practice presented by Daniel Rortvedt. \\ Registration link: https://attendee.gotowebinar.com/ register/5243087562007142145}

Wednesday, September 18, 2019, from 1pm-2pm Eastern Standard Time (EST):

Decent Work, Work Motivation and Psychological Capital: An empirical research presented by Tânia Ferraro.

Registration link: https://attendee.gotowebinar.com/ register/2229869349017379329

Wednesday, October 16, 2019, from 1pm-2pm Eastern Standard Time (EST) 
The impact of customer incivility and verbal aggression on service providers: A systematic review presented by Valentina Sommovigo.

Registration link: https://attendee.gotowebinar.com/ register/1164081940462995457

Wednesday, November 27, 2019, from 1pm-2pm Eastern Standard Time (EST):

Job satisfaction and its related factors among dentists: A cross-sectional study presented by Joanna Kobza.
Registration link: https://attendee.gotowebinar.com/ register/7542927240404548355

As always, I welcome hearing from you.

Cheers,

Karen

Founding Editor, WORK

Occupational therapist \& ergonomist

Kjacobs@bu.edu

blogs.bu.edu/kjacobs/

@WORK_Journal https://www.facebook.com/

WORKJournal2016/?fref=ts 